\title{
Irrigation regime Influence on the growth and seedlings development of common fake chestnut (Aesculus hippocastanum L.) and Japanese safflower (Sophora japonica L.) in the highways landscaping
}

\author{
Farxod Ubaydullaev", Alisher Xoliqov, Sardor Xudaybergenov, and Tojinur Pulatova \\ Tashkent State Transport University, Tashkent, Uzbekistan
}

\begin{abstract}
It is important to accelerate the growth of seeds and seedlings when growing seedlings in forests and orchards in the landscaping of roads and residential areas. One of the effective methods is irrigation in the complex of agro-technical measures to improve the nursery. This shortens the growing time of seedlings and saplings of tree and shrub species, increases their quality while reducing labor costs per unit area.
\end{abstract}

\section{Introduction}

The importance of ornamental trees in ensuring environmental sustainability in the world, landscaping roads, and residential areas is high. Simple fake chestnut and Japanese safflower for landscaping are part of the range of promising ornamental tree species. Fake chestnut and Japanese safflower tree seedlings are grown in many countries in Europe, East Asia and North America in the construction of ornamental gardens and parks, landscaping of residential areas and highways, and as a medicinal tree plant [1-4].

Today, the demand for ornamental trees in the landscaping of settlements in the Republic is growing from year to year. There is a particular need for seedlings of ordinary fake chestnut and Japanese safflower and other beautiful flowering tree species. In 20082012, Uzbekistan was instructed to produce 8.1 million seedlings of Japanese safflower and 1.2 million saplings of ordinary fake chestnut $[5,6]$. Accordingly, the development of intensive agrotechnology for the supply of ornamental tree seedlings following the standard requirements, which is promising and cost-effective for specialists and foresters engaged in ornamental planting, has set an important task [7-10].

\section{Method and Materials}

The assigned tasks were performed using field and laboratory experiments. The climatic conditions of the study area were studied based on data from the Tashkent meteorological station. Experiments on the use of growing substances in the germination of seeds of

* Corresponding author: farxod2477@mail.ru 
ordinary fake chestnut and Japanese safflower were carried out on typical gray soils of the Tashkent region. Experimental field soils contain humus $1.16 \%$, total nitrogen $0.022 \%$, total phosphorus $0.190 \%$, potassium retention $2.51 \%$, amount of mobile nutrients: N-NH3$36.2 \mathrm{mg} / \mathrm{kg}, \mathrm{N}-\mathrm{NO} 3-18.42 \mathrm{mg} / \mathrm{kg}, \mathrm{P} 2 \mathrm{O} 5-32 \mathrm{mg} / \mathrm{kg}$.

Seed analysis was determined using GOST 13056.4-75, standard seedling GOST 331790, standard seedlings GOST 24835-81. Soil and plant analysis in the laboratory of agrochemistry of the Forestry Research Institute on the method "Methods of agrochemical, agrophysical and microbiological research of Central Asia" and "Agrotechnics on intensive cultivation of fake chestnut and Japanese safflower seedlings" [1].

\section{Results and Discussion}

In the cultivation of woody plants in nurseries, the application of advanced agro-technical measures based on soil and climatic conditions gives good results. In growing seedlings, the need for water and nutrients varies in different phases of the plant. Due to this, in the course of our research, agro-technical measures were applied in the application of agro-technical measures to seedlings based on plant and soil requirements during the growth and development phases.

The applied agro-technical measures are mainly aimed at maintaining soil moisture and providing adequate nutrition, and these factors are of particular importance in the growth and development of plants. During our study, soil moisture of ordinary fake chestnut and Japanese sophora seedlings was kept in the order of 50-60\%, 60-70\% and 70-80\% relative to the moisture capacity of the field. At the same time, soil moisture was determined at 0.5 $\mathrm{m}$ in annual seedlings, $0.7 \mathrm{~m}$ in the second and third years, and irrigation norms were set based on this moisture shortage (water use coefficient according to AN Kostyakov was $0.9)$.

Observations to determine soil moisture, in turn, allow to determine the rate and duration of irrigation.

During the study years, pre-irrigation soil moisture was maintained in the order specified in the program relative to the field moisture capacity. The soil samples were placed in a thermostat and dried at a temperature of $+105 \mathrm{C}^{0}$. During our studies, preirrigation soil moisture ranged from 12.26 to $14.1 \%$ to maintain soil moisture at $50-60 \%$ of field moisture capacity, and from $15.32 \%$ to $16.85 \%$ at $60-70 \%$ relative to field moisture capacity and from $17.1 \%$ to $18.68 \%$ when the field moisture capacity was $70-80 \%$. At the same time, irrigation was required 4 times to keep the soil moisture at $50-60 \%$ of the field moisture capacity, 6 times to keep it at $60-70 \%$, and 8 times to keep it at $70-80 \%$. 
Table 1. Soil moisture planted with ordinary fake chestnut and Japanese safflower seeds

\begin{tabular}{|c|c|c|c|c|c|c|c|c|c|}
\hline \multicolumn{2}{|c|}{$\begin{array}{l}\text { Humidity relative to the } \\
\text { moisture capacity of the } \\
\text { field, \% }\end{array}$} & \multicolumn{8}{|c|}{ Periods of soil moisture } \\
\hline \multirow{4}{*}{$50-60$} & Weight, $g$ & 13.33 & 13.11 & 12.26 & 14.10 & & & & \\
\hline & $\begin{array}{c}\text { Moisture } \\
\text { capacity of } \\
\text { the field, in } \%\end{array}$ & 55.55 & 54.6 & 53.77 & 58.00 & & & & \\
\hline & $\mathrm{m}^{3} / \mathrm{ga}$ & 1066.8 & 964.22 & 970.4 & 982.1 & & & & \\
\hline & $\begin{array}{c}\text { Irrigation } \\
\text { period }\end{array}$ & 13.05 & 10.06 & 6.07 & 10.08 & & & & \\
\hline \multirow{4}{*}{$60-70$} & Weight, g & 15.75 & 15.32 & 15.35 & 16.42 & 15.81 & 16.85 & & \\
\hline & $\begin{array}{c}\text { Moisture } \\
\text { capacity of } \\
\text { the field, in } \%\end{array}$ & 65.6 & 63.8 & 63.9 & 68.4 & 65.8 & 70.2 & & \\
\hline & $\mathrm{m}^{3} / \mathrm{ga}$ & 759.7 & 799.3 & 796.5 & 689.0 & 754.2 & 658.4 & & \\
\hline & $\begin{array}{c}\text { Irrigation } \\
\text { period }\end{array}$ & 13.05 & 10.06 & 25.06 & 6.07 & 15.07 & 10.08 & & \\
\hline \multirow{4}{*}{$70-80$} & Weight, $\mathrm{g}$ & 17.56 & 17.9 & 17.1 & 17.5 & 17.60 & 17.55 & 18.68 & 17.20 \\
\hline & $\begin{array}{c}\text { Moisture } \\
\text { capacity of } \\
\text { the field, in } \%\end{array}$ & 73.1 & 74.6 & 71.2 & 72.9 & 73.30 & 73.1 & 77.8 & 71.66 \\
\hline & $\mathrm{m}^{3} / \mathrm{ga}$ & 593.07 & 561.7 & 635.4 & 594.0 & 592.1 & 594.1 & 500.5 & 578.0 \\
\hline & $\begin{array}{c}\text { Irrigation } \\
\text { period }\end{array}$ & 21.04 & 13.05 & 10.6 & 25.06 & 6.07 & 15.07 & 27.07 & 10.08 \\
\hline
\end{tabular}

The minimum moisture capacity of the soil was determined when irrigated 4 times, which was $53.77 \%$. It was observed that the minimum moisture content of the soil after 6 irrigations was $63.8 \%$, and after 8 irrigations, this figure was $71.2 \%$. These data are detailed in Table 1.

During the years of the study, the timing and rate of irrigation were determined based on water availability, with soil moisture determined before each irrigation.

According to the data, to keep the soil moisture at $50-60 \%$ of the field moisture capacity, the soil moisture was $55.5 \%$ when the mass of the dried soil was $13.3 \mathrm{~g}$, and irrigation with $1066.8 \mathrm{~m}^{3}$ / ha to fill the soil moisture deficit

These figures are 15.75 by mass of dry soil, respectively, according to the options, depending on the increase in soil moisture before irrigation; Soil moisture 65.6 at $17.56 \mathrm{~g}$; $73.1 \%, 759.7$ to fill the moisture deficit; It was determined that $593.07 \mathrm{~m}^{3} /$ ha should be irrigated with water.

During our research (2011), the annual rainfall was $255.5 \mathrm{~mm}$, in $2010-388.5 \mathrm{~mm}$. During these years, the experimental fields were irrigated 4,6 , and 8 times to maintain optimal humidity, and each irrigation rate was in the range of $650-700 \mathrm{~m}^{3} / \mathrm{ga}$.

In this case: the first irrigation on soil moisture from April 24 to May 13;

- the second watering is from May 13 to June 10;

- the third from June 10 to July 6;

- the fourth from June 25 to August 10;

- the fifth from July 6 to July 15 ;

- the sixth from July 15 to August 10 ;

- the seventh on July 27-28;

- the eighth was held August 10-11.

When growing three-year-old seedlings of ordinary fake chestnut, keeping the soil moisture at the required level positively affected their growth. 
Leading scientists of the industry Z.B.Ivanova, V.M.Lavrichenko [2; Pp. 100-107] pay special attention to the self-important aspects of the organization of simple fake chestnut agrotechnics, such as the number of forest trees. It is noted that the rapid growth and adaptability of ordinary fake chestnuts to different climatic conditions, like other forest trees, allows achieving the expected result in large nurseries when grown based on agrotechnical requirements.

Based on these data, during our studies, ordinary fake chestnut seeds in different preirrigation soil moisture were irrigated 4 times, 6 times and 8 times with normal irrigation following the soil moisture.

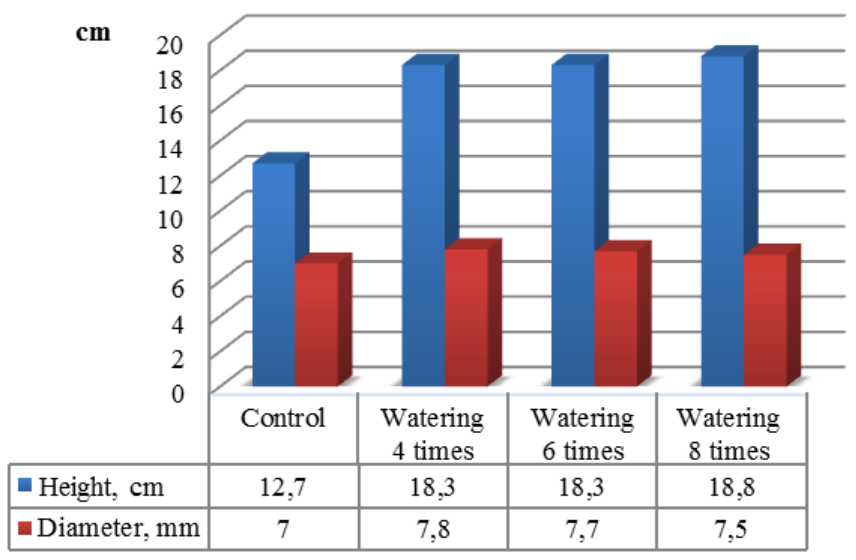

Fig. 1. The effect of irrigation on the growth of annual seedlings of ordinary fake chestnut

When the simple fake chestnut seed seedlings were irrigated 4 times, the plant height was $18.3 \mathrm{~cm}$, and the diameter of the root collar was $7.8 \mathrm{~mm}$. When irrigated 6 times, the plant height was $18.3 \mathrm{~cm}$, and the diameter of the root collar was $7.5 \mathrm{~mm}$. These results showed that when 8 times watered, the plant height was $18.8 \mathrm{~cm}$, and the diameter of the root collar was $7.5 \mathrm{~mm}$ (Figure 1).

The small effect of irrigation on the biometric performance of ordinary fake chestnut seedlings can be explained by the fact that moisture was almost the same effect on seeds sown in spring due to the abundance of rains during the sowing period. Also, the full germination of ordinary fake chestnut seedlings took place in the second decade of May.

Observations and analyzes on the effect of the irrigation regime on the growth and development of Japanese safflower seed seedlings were carried out. This information is detailed in Figure 2.

Fig. 2. The effect of irrigation on the growth of annual seedlings of Japanese sophora

In the 50-60\% variant of the annual Japanese safflower soil moisture relative to the field moisture capacity, the seed height was $130.7 \mathrm{~cm}$, which was $9.2 \%$ higher than the control. In the variant of soil moisture $60-70 \%$ relative to the field moisture capacity, the growth of seedlings was $134.1 \mathrm{~cm}$. In this variant, it was watered 6 times to maintain the specified humidity. When the soil moisture was $70-80 \%$ of the field moisture capacity, it was irrigated 8 times, and the height of the seedlings was $136.8 \mathrm{~cm}$ (see Figure 2).

The high level of soil moisture positively affected the growth of two-year-old ordinary fake chestnut seedlings. In the second year of the study, the pattern was maintained based on the results obtained in the first year. 

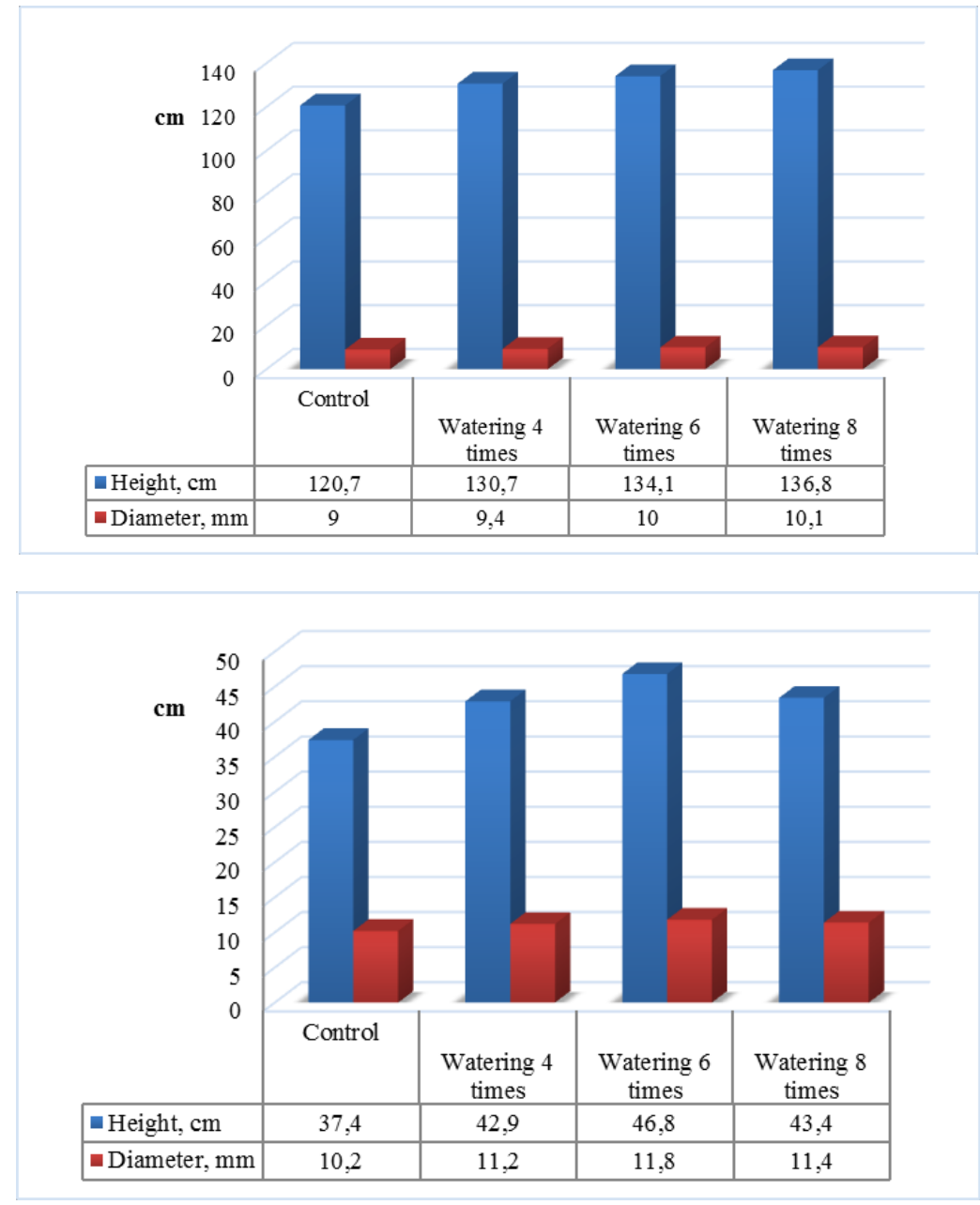

Fig. 3. The effect of irrigation on the growth of biennial seedlings of ordinary fake chestnut

In particular, the growth rates of the plants were high, and they were irrigated 4, 6 and 8 times during the growing season. As a result, the rapid growth of seedlings was ensured, and when irrigated 4 times, the plant reached a height of $42.9 \mathrm{~cm}$ and a diameter of the root collar $11.2 \mathrm{~mm}$. When irrigated 6 times, the plant height was $43.4 \mathrm{~cm}$, and the diameter of the root collar was $11.8 \mathrm{~mm}$. When irrigated 8 times, the growth in height was 46.4, and the diameter of the root collar was $11.4 \mathrm{~mm}$. These values were $37.4 \mathrm{~cm}$ and $10.2 \mathrm{~mm}$ in the control variant, respectively (see Figure 3).

Observations and analysis of the effect of irrigation regime on the growth and development of biennial Japanese safflower seedlings were performed (Figure 4).

Figure 4 The effect of irrigation on the growth of biennial seedlings of Japanese sophora

In the third year of our study, it was observed that the height of the plant and the diameter of the root collar were higher than the control when the simple fake chestnut and Japanese safflower seedlings were watered 4, 6 and 8 times, following the pattern of previous years (see Figures 5, 6, 7). 

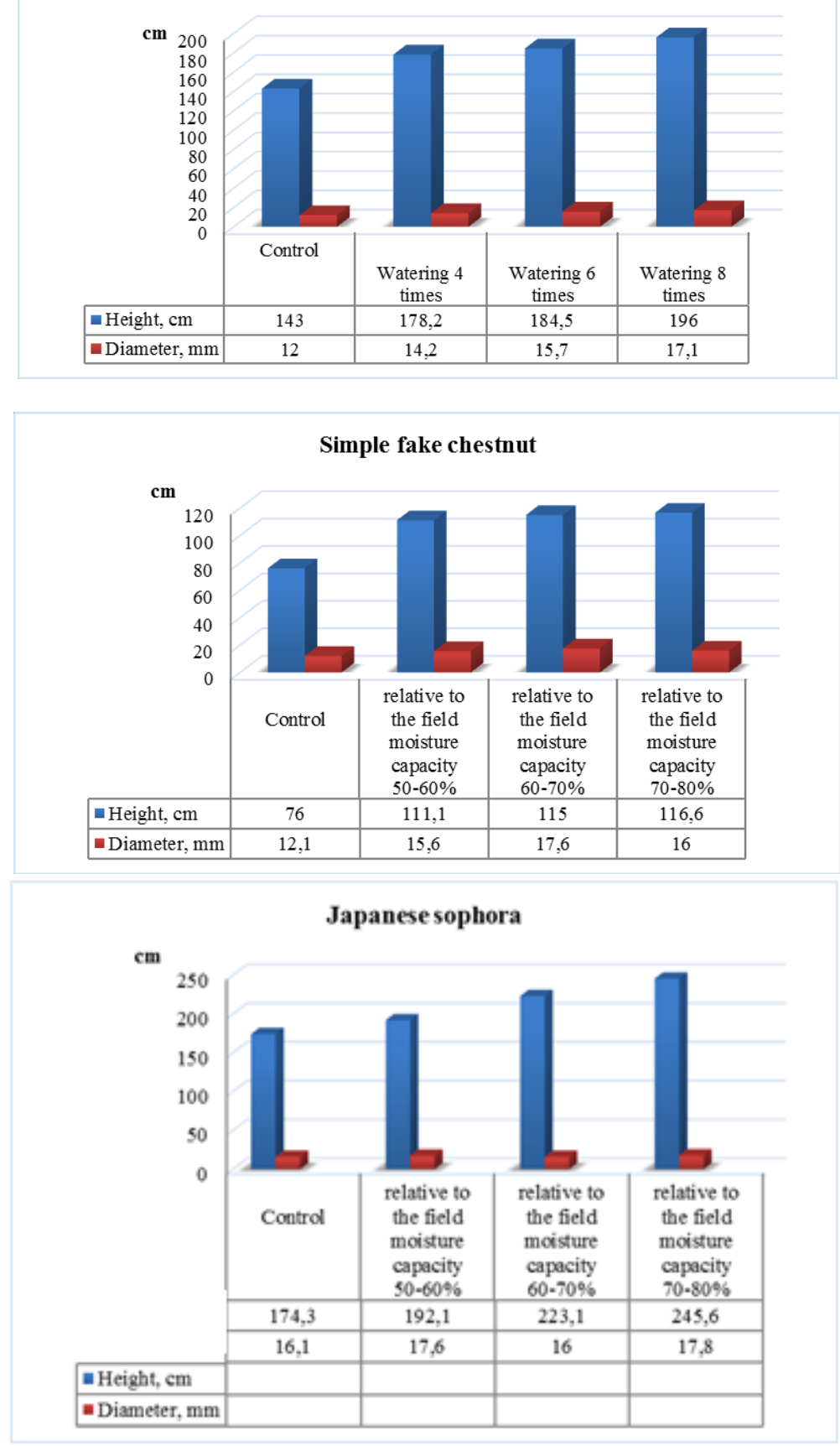

Fig. 5. The effect of irrigation on the growth of three-year seedling of ordinary fake chestnut and Japanese sophora 


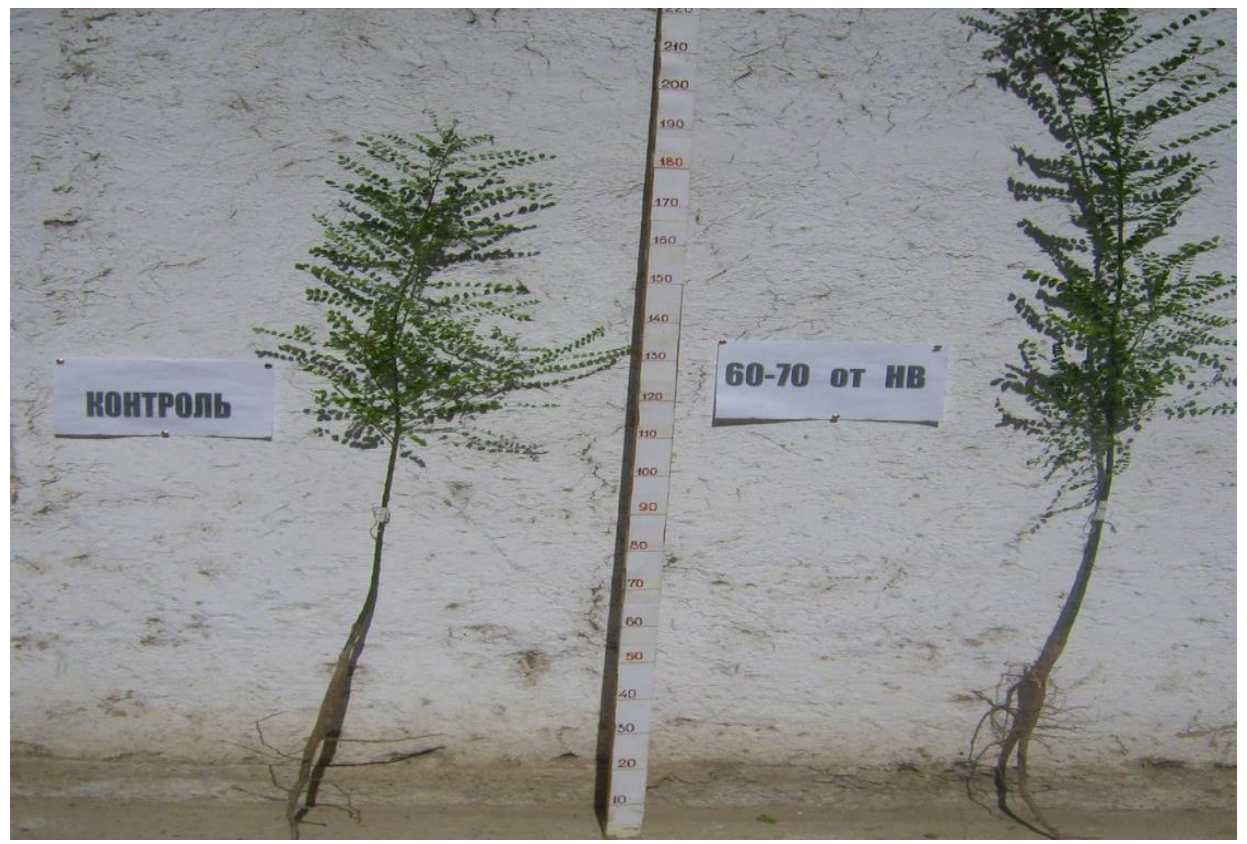

Fig. 6. Appearance of three-year-old Japanese sophora when grown at $60-70 \%$ soil moisture relative to field moisture capacity

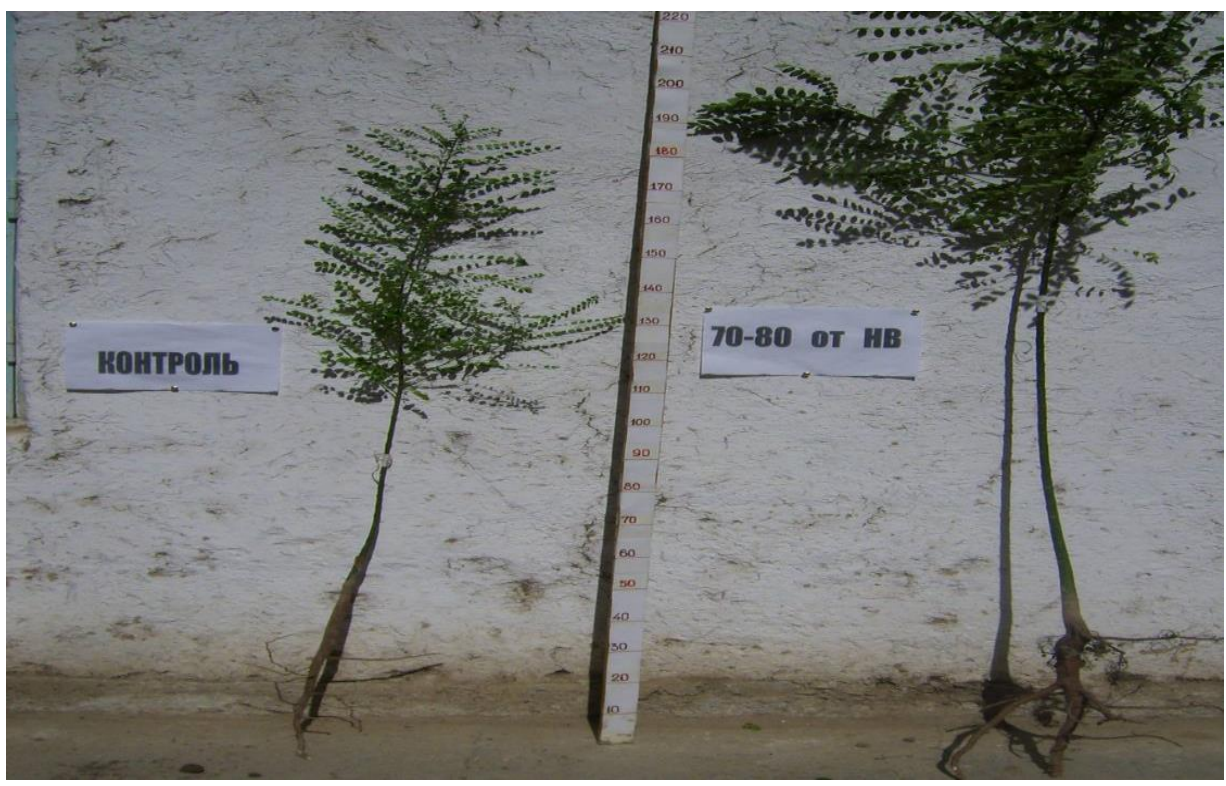

Fig. 7. Appearance of a three-year-old Japanese sophora grown at $70-80 \%$ soil moisture relative to field moisture capacity

The origin of standard seeds from ordinary fake chestnut and Japanese safflower seeds studied over the years of the study was studied. In this case, high-quality, disease-resistant and standard seed seedlings were calculated from seeds when the soil moisture before irrigation was maintained at $50-60 \%, 60-70 \%$ and $70-80 \%$ of the field moisture capacity. 
Standard seeds of ordinary fake chestnut seeds 30 lin. $\mathrm{m}$, the total number of seedlings was 225 when the pre-irrigation soil moisture was kept at $50-60 \%$ of the field moisture capacity, which is 203 seedlings or $9.8 \%$ higher than the control.

When the pre-irrigation soil moisture was maintained at $60-70 \%$ of the field moisture capacity, the total number of seedlings when planted in the normal way was 211 , of which the standard number of seedlings was 195 or $12 \%$ higher than the control. In this order, the soil moisture before irrigation of ordinary fake chestnut seedlings was maintained at 70$80 \%$ of the field moisture capacity, 238 seedlings and 215 seedlings of standard seeds or $10.1 \%$ higher than the control.

During our study, the standard seeds of Japanese safflower seeds were 20 lin. m, when the pre-irrigation soil moisture was kept at 50-60\% of the field moisture capacity, 194 seedlings and the resulting standard seedlings were 186 or $10.2 \%$ higher than the control.

When the pre-irrigation soil moisture was maintained at $60-70 \%$ of the field moisture capacity, the total number of seedlings was 175 , of which the standard number of seedlings was 159 or $10.3 \%$ higher than the control.

In the same way, the total number of seedlings was 187 when the pre-irrigation soil moisture was kept at $70-80 \%$ of the field moisture capacity, which shows that the number of standard seedlings was 177 or $11.1 \%$ higher than the control.

Table 2. Influence of different irrigation regimes on ordinary fake chestnut and Japanese safflower seedlings on standard seed germination

\begin{tabular}{|c|c|c|c|c|c|}
\hline \multirow{3}{*}{$\begin{array}{c}\text { The amount of } \\
\text { irrigation }\end{array}$} & \multicolumn{3}{|c|}{$\begin{array}{c}\text { The number of plants in the } \\
\text { experiment }\end{array}$} & \multirow{3}{*}{$\mathrm{P}$} & \multirow{3}{*}{$\mathrm{T}$} \\
\hline & \multirow{2}{*}{ total pieces } & \multicolumn{2}{|c|}{ hence the standards } & & \\
\hline & & pieces & $\%$ & & \\
\hline \multicolumn{6}{|c|}{ Simple fake chestnut (30 lin. $\mathrm{m}$ account) } \\
\hline Control & 250 & 201 & $80.4 \pm 2.4$ & 2.25 & 1.1 \\
\hline 4 & 225 & 203 & $90.2 \pm 1.98$ & 2.2 & 1.0 \\
\hline 6 & 211 & 195 & $92.4 \pm 1.83$ & 2.0 & 0.2 \\
\hline 8 & 238 & 215 & $90.3 \pm 1.90$ & 2.1 & 2.0 \\
\hline \multicolumn{6}{|c|}{ Japanese sophora (20 lin. m account) } \\
\hline Control & 200 & 162 & $81.0 \pm 2.2$ & 2.4 & 1.6 \\
\hline 4 & 194 & 186 & $91.2 \pm 1.92$ & 2.1 & 1.2 \\
\hline 6 & 175 & 159 & $91.3 \pm 1.92$ & 2.3 & 2.2 \\
\hline 8 & 187 & 177 & $92.2 \pm 1.83$ & 2.3 & 0.11 \\
\hline
\end{tabular}

In our observations of subsequent years of research on pre-irrigation soil moisture and seedling thickness, the results were obtained on the options while maintaining the above pattern. These results are detailed in Table 2.

The results show that each irrigation has a specific effect on plant growth when the soil moisture before irrigation for the cultivation of standard seedlings of ordinary fake chestnut is maintained at $60-70 \%$ of the field moisture capacity and watered 6 times during the growing season, each irrigation 750-800 $\mathrm{m} 3 /$ ha water consumption, for Japanese safflower, the field is irrigated 8 times when kept at $70-80 \%$ of moisture capacity, and $750-800 \mathrm{~m} 3$ / ha water consumption is required for each irrigation, which is optimal for seedling growth and development conditions occurred. 


\section{Conclusions}

When ordinary fake chestnut and Japanese safflower seeds are kept at 50-60\%, 60-70\% and $70-80 \%$ of soil moisture relative to the field moisture capacity, the option of holding ordinary fake chestnut seeds at $60-70 \%$ relative to the field moisture capacity is higher than other options found to be $116.6 \mathrm{~m}$ in height and $16 \mathrm{~mm}$ in diameter, while in control, the growth was $76 \mathrm{~cm}$ and $12.1 \mathrm{~mm}$ in diameter. The Japanese safflower kept the seeds at 70 $80 \%$ of the field moisture capacity, which was higher than the other options, with a height of $245.6 \mathrm{~m}$ and a diameter of $17.8 \mathrm{~mm}$, while in control, the growth was $174.3 \mathrm{~cm}$ and 16,1 $\mathrm{mm}$ in diameter was found to be.

\section{References}

1. S.K.Kojaxmetov, V.P.Fimkin, Ya.Yu.Musaev, X.K.Yuldashev, F.B.Ubaydullaev false chestnut and Japanese Sophora intensive farming on the recommendation // grow seedlings of forestry research institute, pp. 5-15, Tashkent, (2017)

2. Ivanova Z.V., Lavrichenko V.M. Diagnostics potrebnosti lesa v pitanii i udobrenii, Vest. s.-x. Nauki, № 2, pp. 100-107. Moscow, (1975)

3. Aggarwal S. Indian dye yielding plants: Efforts and opportunities, Natural Resources Forum, Oxford, UK : Blackwell Publishing Ltd, 45(1), pp. 63-86, (2021)

4. Sytar, Oksana. The involvement of different secondary metabolites in salinity tolerance of crops." Salinity Responses and Tolerance in Plants, Volume 2. Springer, Cham, pp. 21-48, (2018)

5. Matyakubov B., Begmatov I., Raimova I. and Teplova G. Factors for the efficient use of water distribution facilities. IOP Conf. Ser. Mater. Sci. Eng. 883, 012025 (2020).

6. Uralov B., Rakhmatov N., Khidirov S., Uljaev F., Raimova I. Hydraulic modes of damless water intake. IOP Conf. Ser. Mater. Sci. Eng. 1030(1), 012123 (2021)

7. Qiao X. Extraction, separation, detection, and structural analysis of flavonoids, Current Organic Chemistry, 15(15), pp. 2541-2566, (2011)

8. Xin I., and Xin-quan ZHANG. Important Functions of Herbs in Rectifying Desertification as well as Slope Protection and Landscaping for Highways and Railways." Journal of Sichuan Grassland 5, (2003)

9. Umurzakov U., and Djuraev B. Prediction of prices for agricultural products through markov chain model, International Journal of Psychosocial Rehabilitation, 24(3), pp. 293-303, (2020)

10. Ahmad S. et al. Transplanted fine rice (Oryza sativa L.) productivity as affected by plant density and irrigation regimes, International Journal of Agriculture and Biology, 7(3), pp. 445-447, (2005) 